\title{
Bilateral Spontaneous Hyphaema in Juvenile Xanthogranuloma: A case report and literature review
}

\author{
AO Adio FWACS, FMCophth; B Fiebai FMCophth; GI Nathaniel, MBBS
}

Department of Ophthalmology, University of Port Harcourt Teaching Hospital, Port Harcourt, Rivers State

\section{SUMMARY}

Background: A four-month-old Nigerian male was presented with spontaneous hyphaema in both eyes initially thought to be due to trauma or possibly non accidental injury. There was associated secondary glaucoma and skin lesions typical of juvenile xanthogranuloma. This condition, to the best of our knowledge, has not yet been reported in Nigeria.

Case report: There was redness in the right eye with no associated tearing or photophobia. On examination, there was visually directed reaching in both eyes, with central, steady and maintained fixation, corneal haze and 15\% hyphaema. The left eye, which appeared normal, later also developed 10\% hyphaema, upon which an impression of juvenile xanthogranuloma was entertained. Laboratory investigations, including a clotting profile, were all within normal limits. Examination under anaesthesia showed progressively increasing buphthalmos and vitreous haemorrhage in the left eye with high intraocular pressure and large cup disc ratios.

Histology showed irregularly disposed spindle-shaped cells in the dermis that were intimately associated with small capillaries containing red blood cells. Occasional tuton-like giant cells were seen with hyperkeratosis and papillomatosis of the epidermis which is consistent with juvenile xanthogranuloma.

Conclusion: Ocular complications provide the primary concern in this condition and could eventually lead to blindness. Therefore, a high index of suspicion is the key to the prevention of blindness.

Key words: juvenile xanthogranuloma, hyphaema, glaucoma

\section{INTRODUCTION}

Juvenile xanthogranuloma (JXG), previously known as nevoxantho-endothelioma, is a benign non Langerhans histiocytic skin disorder mainly manifesting during infancy with the mean age of presentation at 22 months. Ten per cent of cases exhibit ocular features. ${ }^{1}$ These ocular manifestations can lead to severe blinding complications such as uveitis, hyphaema and secondary glaucoma. ${ }^{1,2,3}$

This condition usually regresses spontaneously by the age of 5 years; however children with ocular complications will continue to live with the socioeconomic and psychologic effects of visual impairment. This condition has to the best of our knowledge not been reported before in Nigeria.

\section{CASE REPORT}

A four-month-old Nigerian male presented to us with a 5-day history of redness in the right eye associated with an abrasion on the left ring finger presumed to be due to trauma, as the child had been left with a minder. There was no associated tearing or photophobia.

Pregnancy history revealed that there was an attempt to abort the pregnancy in the first trimester as the pregnancy occurred out of wedlock.

On examination, there was visually directed reaching in both eyes, with central, steady and maintained fixation. There was mild conjunctival infection of the right eye, corneal haze and $15 \%$ hyphaema. Patient was then admitted and managed as a case of possible right traumatic hyphaema. The left eye appeared normal. Painless brown, roundish papules, about $3 \mathrm{~mm} \times 3 \mathrm{~mm}$ in size, were observed on the head and trunk (see figure 1). He was nursed with head elevation at 30 degrees. Timolol, atropine, maxitrol eye drops and oral acetazolamide $62.5 \mathrm{mg}$ were administered twice daily. A week later, the patient developed a 30\% hypopyon in the left eye and the right hyphaema remained at the same level. At this point, a diagnosis of masquerading syndrome (that is, a posterior segment infection, inflammation or malignancy) was entertained and systemic cefuroxime and topical ciprofloxacin were added. Six days later, the hypopyon resolved but the patient developed a $10 \%$ hyphaema in the left eye. A suspicion of juvenile xanthogranuloma was entertained.

Laboratory investigations carried out included a full blood count with clotting profile, ESR, electrolyte urea and

${ }^{*}$ Correspondence: B Fiebai, Department of Ophthalmology University of Port Harcourt Teaching Hospital, Port Harcourt, Rivers State 
creatinine, ocular ultrasound scan and retroviral screening. None of these investigations produced any abnormal results.

An examination under anaesthesia showed vertical corneal diameters of $11 \mathrm{~mm}$ in both eyes and horizontal diameter of $11.5 \mathrm{~mm}$ in the right eye and $12 \mathrm{~mm}$ in the left. There was a fibrin clot in the right anterior chamber and $30 \%$ hyphaema in the left (see figure 2). The left eye had vitreous haemorrhage with no red reflex. The right eye revealed pale discs with a cup disc ratio of 0.7 . Intraocular pressure by applanation tonometry was $38 \mathrm{mmHg}$ in the right eye and $41 \mathrm{mmHg}$ in the left eye. Peribulbar depot steroids were given in both eyes. Oral acetazolamide was increased to $62.5 \mathrm{mg}$ three times daily, and timolol eye drops were continued.

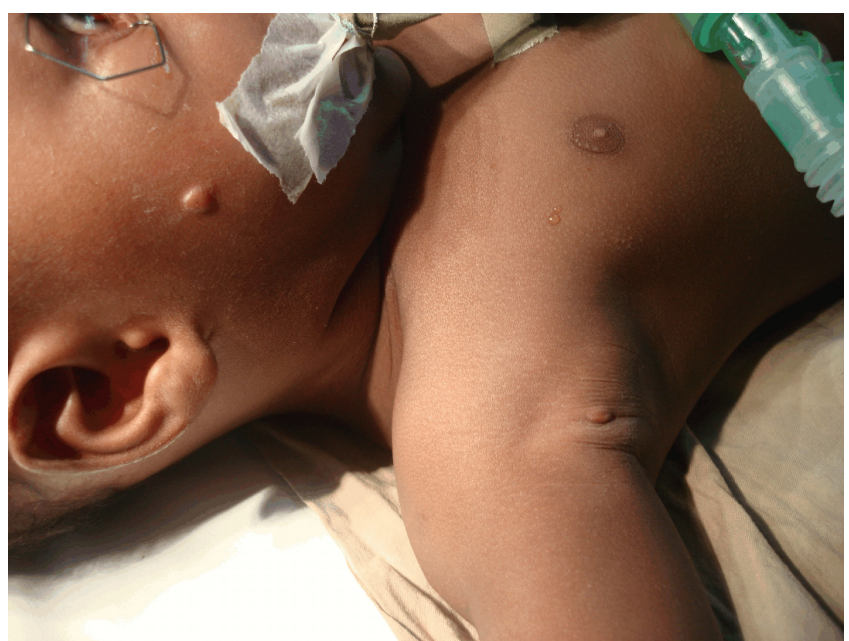

Figure 1. Skin lesions on head and right armpit.

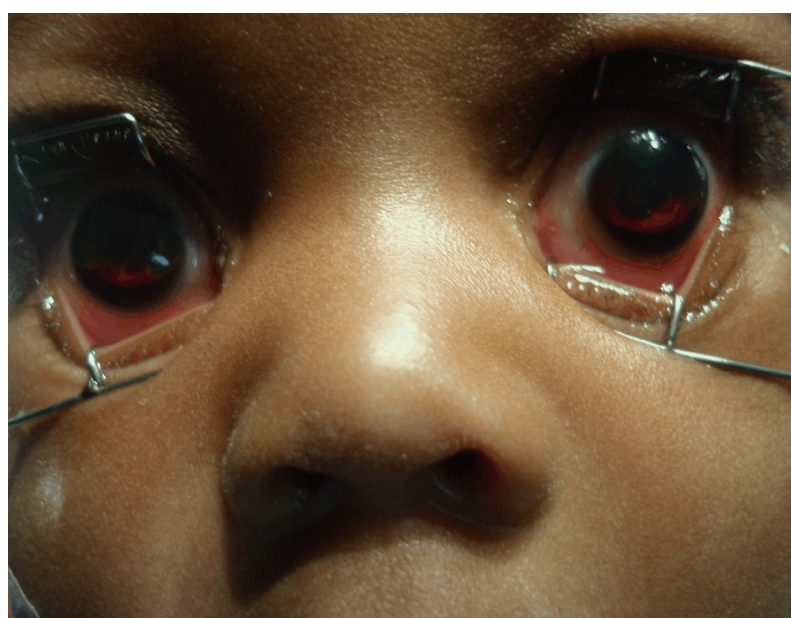

Figure 2. Close view of bilateral spontaneous hyphaema in a 4 month old.

Intraocular pressure in both eyes was checked 2 weeks after, and found to be $8 \mathrm{mmHg}$ in the right eye and $20 \mathrm{mmHg}$ in the left eye. Examination under anaesthesia showed fibrin clots in the anterior chamber in both eyes. The vitreous haemorrhage in the left eye had resolved and revealed a cup disc ratio of 0.8 in the left eye. There was an increase in the vertical and horizontal corneal diameters of both eyes to $13 \mathrm{~mm}$. A trabeculectomy was then planned for the patient.

Histology results of the skin lesions showed irregularly disposed spindle-shaped cells in the dermis that were intimately associated with small capillaries containing red blood cells. Occasional tuton-like giant cells were seen with hyperkeratosis and papillomatosis of the epidermis. This is consistent with juvenile xanthogranuloma (see figure 3).

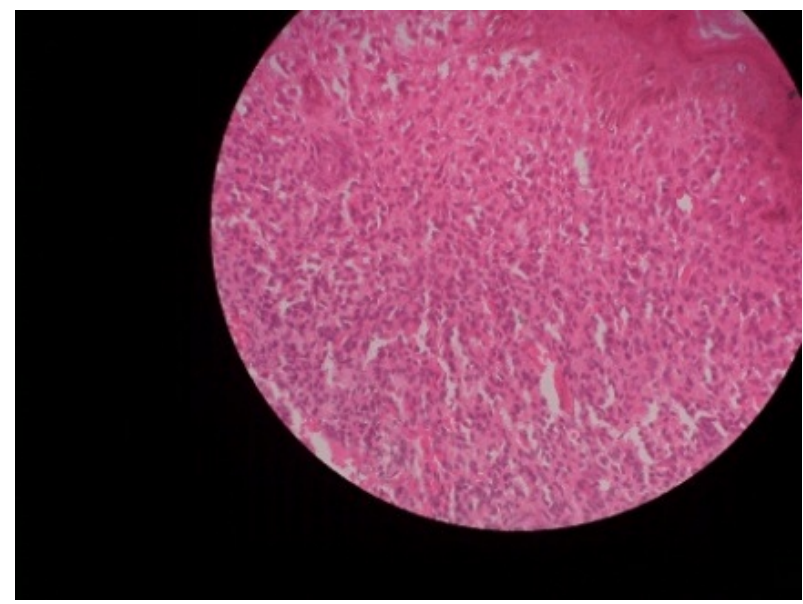

Figure 3. Histopathological features of the shave excision biopsy of one of the skin papules.

A repeat examination was done under anaesthesia on 12/03/08; the corneal diameter had returned to normal and the media in both eyes were now clear. The cup disc ratio was 0.3 for the RE and 0.7 for the LE. The IOP was now 4 and 8 $\mathrm{mmHg}$ for the RE and LE respectively. The trabeculectomy was postponed due to financial constraints and since the medications were controlling the pressures in the absence of fresh bleed.

\section{DISCUSSION}

Juvenile xanthogranuloma (JXG) is a self-limiting dermatologic disorder with rare systemic manifestations affecting mainly infants and small children. ${ }^{2}$ Thirty-one per cent of cases occur at birth and 71 per cent in the first year of life.

The frequency of occurrence is not known but it is believed to be higher than reported. It is more common among Caucasians than Blacks. There were no reported cases of this condition seen during an extensive search locally and in Africa. This is probably due to misdiagnosis as a result of its early presentation in life and due to spontaneous regression of the cutaneous lesions.

The aetiology is unknown but is believed to be the result of a disordered macrophage response to nonspecific tissue 
injury. ${ }^{2}$ It is postulated that JXG is a granulomatous reaction of histiocytes to an unidentified stimulus of possibly a physical or infectious aetiology. A physical injury may have played a part in the aetiology of the patient, as there was a history of an attempted abortion of the pregnancy. Krause et al. suggest a possible CD4+ plasmatoid monocyte origin. ${ }^{4}$

Cutaneous JXG is reported to be 1.5 times more common in males than females. Multiple Cutaneous lesions are seen more often in male than female patients. The patient in this study is male and had multiple cutaneous lesions. Children at maximum risk of ocular complications and multiple skin lesions are those aged 2 years or younger. ${ }^{3}$

The disorder typically manifests as cutaneous lesions. The lesions may be single or multiple and consist of firm, rubbery papulonodules several millimetres in diameter. They typically occur on the head and neck and there could also be extracutaneous sites such as the eyes, particularly the uveal tract. The patient had about six cutaneous lesions, mainly on the head and neck and a few on the trunk. Histological examination of the lesions confirmed JXG.

Approximately $50 \%$ of patients with ocular involvement have skin lesions. The incidence of ocular complications in patients with cutaneous JXG is $0.3 \% .^{2}$ Juvenile xanthogranuloma is the most frequent cause of spontaneous hyphaema in children and is complicated by secondary glaucoma and blindness. Glaucoma could also result from accumulation of histiocytes in the angle structures. ${ }^{5}$ Other protean ocular manifestations include masquerading uveitis, heterochromia and posterior segment involvement. ${ }^{5}$

A masquerading uveitis was the initial manifestation in the patient and there was heterochromia irides in the left eye. The heterochromia is believed to have resulted from a diffuse infiltration of the iris by the histiocytes.

The main complication in the patient was secondary glaucoma, which was managed by systemic and topical intraocular pressure lowering drugs until a trabeculectomy could be performed. Peribulbar and topical steroids were used to control uveitis which was also a challenge in the management of this patient.

Juvenile xanthogranuloma, though a self-limiting benign condition may cause severe visual impairment as a result of complications of its ocular manifestation if not treated early.

\section{CONCLUSION}

The diagnosis of juvenile xanthogranuloma must be entertained early in any case of spontaneous hyphaema particularly in infants.

As a greater percentage of these cases occur in childhood, children could be another statistic in undiagnosed causes of blindness. There is, therefore, a need for a high index of suspicion so that these children are identified early and the blinding complications prevented.

\section{REFERENCES}

1. Vendal Z, Walton D, Chen T. Glaucoma in juvenile xanthogranuloma. Semin Ophthalmol 2006; (21)3: 191-4.

2. Curtis T. Juvenile xanthogranuloma (homepage on the internet). (Updated 2006 Sept 29; cited 2007 Nov 14).Available from http://www.emedicine.com

3. Chang MW, Frieden IJ, Good W. The risk of intraocular juvenile xanthogranuloma: survey of current practices and assessment of risk. J Am Acad Dermatol 1996; 34(3): 445-9.

4. Kraus MD, Haly JC, Ruiz R, Essay L, Moran CA, Fletcher CD. Juvenile xanthogranuloma: An immunophenotypic study with a reappraisal of histogenesis. Am J Dermatopathol 2001; 23(2): 104-11.

5. Harley's Book on Glaucoma in Infants and Children. In: Nelson LB, Olitsky SE, eds. Paediatric Ophthalmology $5^{\text {th }}$ edition. 2005 p.294.

6. Zamir E, Wang RC ,Krishnakumar S, Aeillo, Leverant A, Dugel $\mathrm{PU}$, Rao NA. Juvenile xanthogranuloma masquerading as paediatric chronic uveitis; A clinicopathologic study. Surv Ophthalmol 2001; 46(2): 164-71. 